\title{
O Papel das Normas de Repetição Obrigatória na Autonomia Estadual ${ }^{1}$
}

\author{
Eduardo Rocha Dias ${ }^{2}$ \\ Ana Cristina Viana Loureiro Gonçalves ${ }^{3}$
}

\section{RESUMO}

\section{As normas de reprodução obrigatória são aquelas de observância} compulsória no texto constitucional estadual e decorrem da subordinação aos princípios consagrados na Constituição da República, de acordo com o comando inserido no Artigo 25, caput, da Constituição Federal de 1988. Cabe ao constituinte decorrente, em relação a tais normas, inseri-las no ordenamento constitucional do Estado, por um processo de transplantação. As normas de repetição obrigatória se espraiam no texto constitucional, muitas vezes estando implícitas nele, o que dificulta a missão do exegeta em perceber quando é o caso de sua aplicação ou não. Surgem, então, os seguintes questionamentos: Qual a função das normas de repetição obrigatória? Como identificá-las? Quais paradigmas devem ser adotados para que a aplicação desse princípio não implique num esvaziamento da autonomia do Estado-membro? Responder a estas indagações é importante, na medida em que a aplicação desse princípio incide sobre autonomia estadual e na caracterização do modelo de Estado brasileiro. No desenvolvimento do estudo foram realizadas pesquisas bibliográficas e documentais em artigos de periódicos, livros de doutrina, leis e regulamentações, com o objetivo de ampliar o conhecimento sobre

1 Data de recebimento: 15/12/2017. Data de aceite: 19/01/2018.

2 Doutor em Direito pela Universidade de Lisboa; Professor do Programa de Pós-Graduação em Direito Constitucional da Universidade de Fortaleza - UNIFOR; Procurador Federal. e-mail: eduardodias@agu.gov.br

3 Mestre em Direito Constitucional pela Universidade de Fortaleza; Analista Ministerial do Ministério Público do Estado do Ceará. e-mail: cristinaviana1505@gmail.com 
a matéria, numa abordagem qualitativa, exploratória, descritiva e explicativa. Após a introdução, o texto trata das concepções de autonomia dos entes federados e de normas de repetição obrigatória. Em seguida, apresenta o resultado do levantamento das recentes decisões do Supremo Tribunal Federal. Concluiu-se pelo papel limitante das normas de repetição obrigatória à autonomia estadual, o que demanda a ponderação no uso dos princípios constitucionais da autonomia e da simetria.

Palavras-chave: federalismo; norma de repetição obrigatória; autonomia estadual.

\section{INTRODUÇÃO}

As normas de reprodução obrigatória são aquelas de observância compulsória no texto constitucional estadual, e decorrem da subordinação aos princípios consagrados na Constituição da República, de acordo com o comando inserido no Artigo 25, caput, da Constituição Federal de 1988. Ao constituinte decorrente cabe inseri-las no ordenamento constitucional do Estado, por um processo de transplantação. Essas normas estão dispersas no texto constitucional, muitas vezes estando implícitas nele, o que dificulta fixar a priori quais são as de aplicação obrigatória ou não. Destaque-se que a Constituição Federal garante a autonomia dos entes federativos, mediante o reconhecimento a eles de poderes de auto-organização, autorregulação e autogoverno. Contudo, essa autonomia não se dissocia do dever de observância aos princípios consagrados na Carta Magna, o que leva à necessidade de compreender a questão da autonomia dos Estados-membros no Brasil, a função das normas de repetição obrigatória, como se identificam tais normas, e o que se deve fazer para que não haja um esvaziamento da autonomia dos Estados-membro. 


\section{DA AUTONOMIA DOS ESTADOS-MEMBROS}

Originariamente, o Estado Federal se baseia na associação de vários Estados que consentem em formar um corpo político maior, mantendo, cada um, seu ordenamento jurídico, político e constitucional próprios, de acordo com as normas estabelecidas por uma Constituição (HORTA, 1991, p. 249).

A autonomia dos Estados que a compõem é, portanto, preexistente à criação da Federação:

Esta forma de governo é uma convenção segundo a qual vários corpos políticos consentem em se tomar cidadãos de um Estado maior que pretendem formar. É uma sociedade de sociedades, que formam uma nova sociedade, que pode crescer com novos associados que se unirem a ela. (MONTESQUIEU, 2015, p. 62).

Por meio da celebração do pacto federativo, esses entes autônomos assentem com a formação de um novo Estado, cujas regras de convivência se encontram no documento que o constitui. Tal forma de estabelecimento da Federação é qualificada como federalismo perfeito, e tem como exemplo clássico o modelo federalista adotado nos Estados Unidos, em que se verificou a anuência formal de cada Estado-membro, outrora soberanos, àquela aliança, pela qual cederam parte de sua autonomia a um ente central, mas que ainda se mantêm como entidades federativas autônomas (MIRANDA, 2007, p. 57).

O Estado Federal assenta-se, portanto, numa estrutura de sobreposição - que comporta os poderes políticos locais (isto é, dos Estados federados) - na qual cada cidadão fica simultaneamente sujeito a duas Constituições - à Federal e à do Estado federado a que pertence (MIRANDA, 2007, p. 195).

No Brasil, o federalismo surgiu da transformação de um Estado unitário em Estado federado. A organização do Estado brasileiro 
como Federação se iniciou com a Proclamação da República, em 1889, de forma expressamente prevista no Decreto $n^{\circ} 1$, de 15 de novembro daquele ano. Aludido texto teve caráter constitucional, pois nele foram estabelecidas novas instituições políticas para o Brasil, sobretudo a república e a federação ${ }^{4}$ (MORAES FILHO, 2009, p. 54).

Essa origem centrífuga da Federação ocorreu também na Áustria, onde a assunção de parcela do poder estatal pelos Estados foi reconhecida por lei aprovada pela Assembleia Nacional Provisória, de 18 de novembro de 1918, concedendo certos direitos legislativos às Assembleias Estaduais e sujeitando os governos estaduais ao governo central. A forma federativa foi reconhecida definitivamente pela Lei de $1^{\circ}$ de outubro de 1920 , sendo a Constituição Federal da Áustria exemplo de "lei de um Estado unitário que se transformou em Estado federativo" (KELSEN, 2013, p. 06), tal como ocorreu no Brasil, em 1891.

O fundamento de validade das Constituições dos Estados-membros, nesses casos, se acha na vontade do Estado unitário, não havendo como se cogitar a soberania plena ou parcial dos Estados-membros, cuja competência deriva diretamente da Constituição Federal, que, também, a concede (KELSEN, 2013, p. 07), cabendo somente reconhecer sua autonomia.

Esse processo de implantação da federação se reflete na tendência centralizadora do poder no plano federal. Com isso, percebe-se a necessidade de distribuir de maneira equilibrada as competências entre os entes federativos, segundo as normas estipuladas na Constituição, a fim de assegurar a descentralização territorial do poder político, evitando a centralização política presente nos Estados unitários (ISMAEL, 2009).

A descentralização do poder político pode ser percebida na Carta de 1988, a qual, dentre outras previsões, estipula que os Estados-

4 Art $1^{\circ}$ - A Nação brasileira adota como forma de Governo, sob o regime representativo, a República Federativa, proclamada a 15 de novembro de 1889, e constitui-se, por união perpétua e indissolúvel das suas antigas Províncias, em Estados Unidos do Brasil (BRASIL. Constituição, 1889). 
-membros se organizam e sejam regidos pelas Constituições e leis que adotarem, devendo observar os princípios contidos na própria Constituição Federal (art. 25, CF/1988).

Com a descentralização territorial, o poder passa a ser exercido também pelos Estados federados, aos quais é atribuída autonomia, configurada pela capacidade de ação e vontade própria, segundo parâmetros estabelecidos pela Constituição Federal. A autonomia confere liberdade de regular a própria conduta, prover e gerir os próprios interesses. Há um poder de organização própria; de estatuir legislação peculiar, de caráter geral, impessoal cogente e abstrato, no seu âmbito territorial; de gerir os próprios negócios, pela ação administrativa do Governador, com base nas competências administrativas, legislativas e tributárias, previstas na Constituição Federal; de organizar seu governo mediante a eleição de representantes, seja no campo Executivo quanto Legislativo, bem como o seu Judiciário (BULOS, 2010, p. 902/903).

\section{DAS NORMAS DE REPRODUÇÃO OBRIGATÓRIA}

A autorização para que os Estados se organizem, e sejam regidos por suas próprias Constituições, e pelas leis que adotarem, decorre diretamente da norma constitucional e nela encontra seus limites. Nessa perspectiva, o poder constituinte dos Estados não é originário, mas decorre da Constituição Federal. Além disso, ao estipular que as Constituições Estaduais devem observar os princípios da Constituição Federal, percebe-se de forma clara que o poder de auto-organização concedida aos Estados não é irrestrito.

O poder constituinte originário é aquele que reflete a ruptura da ordem jurídica existente e cria um novo tipo de Estado, com uma nova Constituição, substituindo a anterior. Ainda que seja o mesmo povo, o mesmo território e que o Estado seja historicamente existente, a manifestação constituinte, ao produzir uma nova Constituição, faz 
nascer um Estado juridicamente novo. Significa dizer que o poder constituinte originário não está sujeito a nenhuma imposição jurídica anterior, não conhece limites para atuar. É livre para escolher a forma de organização do Estado, federal ou o unitário, os objetivos do Estado, e os valores devem ser assegurados na Constituição. Não há nenhum comprometimento com a ordem anterior, nem mesmo com o ato de sua convocação.

O Ato das Disposições Constitucionais Transitórias fixou o agente do poder constituinte decorrente e o prazo para a elaboração das Constituições Estaduais: "Cada Assembleia Legislativa, com poderes constituintes, elaborará a Constituição do Estado, no prazo de um ano, contado da promulgação da Constituição Federal, obedecidos os princípios desta" (art. 11). O exercício do poder constituinte estadual é, portanto, exercido por um órgão representativo, cujos membros são eleitos pelo povo, que elabora e promulga a Constituição, no caso, as Assembleias Legislativas.

Com isso, pode-se afirmar que o poder constituinte estadual guarda características semelhantes à do poder reformador: é secundário, subordinado, condicionado e contínuo. ${ }^{5}$ Trata-se, portanto, de um poder conferido juridicamente, que não existe por si, visto ter sido criado pelo poder constituinte originário.

Ao contrário do poder constituinte originário, o poder constituinte estadual, embora tenha certa liberdade criativa para elaborar suas Constituições, não inaugura, não instaura, não implanta uma nova ordem jurídica, pois encontra sua base na Constituição Federal. Ainda que esse poder seja incumbido da primeira Carta Constitucional Estadual, ele, necessariamente, conformará os Estados-membros aos critérios estabelecidos na própria Constituição Federal. "A Constituição federativa deve ser composta por Estados da mesma natureza,

5 Bulos (2010, p. 411) explica o porquê desses atributos: secundário, porque advém da Constituição Federal; subordinado, por estar submetido aos princípios constitucionais federais; condicionado, pois a alteração das cartas estaduais sujeitam-se aos parâmetros da Constituição Federal; e contínuo, em razão do dever de, ao reformar as Constituições dos Estados-membros, atualizar e complementar a obra do constituinte estadual, sem alterar as suas bases. 
principalmente por Estados republicanos" (MONTESQUIEU, p. 63).

Para promover essa conformação dos Estados aos princípios estabelecidos na Constituição Federal, faz-se necessário primeiro compreender quais princípios são aplicáveis compulsoriamente aos Estados. E para compreendê-los, é necessário alcançar uma compreensão da própria norma constitucional "como Constituição política capaz de se converter num plano nomativo-material global, que eleja fins, estabeleça programas e determine tarefas". Mesmo onde a norma parece clara, há necessidade da atividade interpretativa, pois, a princípio, todos os textos jurídicos são suscetíveis e carecem de interpretação (COELHO, 2000, p. 26).

No Estado Federal, os Estados-membros não são soberanos, gozando apenas de autonomia. Isto implica dizer que sua esfera de autodeterminação está sujeita a um conjunto de limitações e restrições. Esse conjunto de limitações extraídas da própria Constituição Federal são denominados normas de observância obrigatória, que nada mais são que normas limitativas da autonomia dos Estados (SILVA, 1997, p. 610).

É interessante perceber certa proximidade entre tal limitação e a chamada supremacy clause, existente no federalismo norte-americano. Trata-se da aplicação da previsão do art. VI da Constituição Norte-americana, que prevê que "Esta Constituição e as leis complementares e todos os tratados já celebrados ou por celebrar sob a autoridade dos Estados Unidos constituirão a lei suprema do país; os juízes de todos os Estados serão sujeitos a ela, ficando sem efeito qualquer disposição em contrário na Constituição ou nas leis de qualquer dos Estados". Em razão de citado dispositivo, juízes dos Estados devem observar a Constituição Federal e esta, bem como a legislação elaborada com fundamento nela, prevalece sobre a legislação dos Estados-membros. Sobretudo a partir da decisão proferida no caso McCullosh v. Maryland, reconheceu-se que tal preeminência decorre, não apenas de poderes expressos, mas também implícitos atribuídos ao Governo Federal. 
Assim, o Direito Federal constitui a supreme law of the land, mecanismo que no Brasil se manifesta na atribuição de competências à União e também na possibilidade de controle de constitucionalidade de leis e atos normativos estaduais face à Constituição Federal. Merece destaque, porém, entendimento de que a supremacy clause também ampararia o controle de constitucionalidade de legislação federal que violasse a autonomia dos Estados-membros (CLARK, 2003, p. 43). Ou seja, ao condicionar a supremacia da legislação federal à sua compatibilidade com a Constituição Federal, ela acaba limitando os poderes da esfera federal, e afirmando uma margem de autonomia para os Estados-membros.

O fundamento jurídico da Federação não se respalda somente na existência de um acordo entre Estados, mesmo porque, também na Confederação, vê-se a celebração de um pacto, mas a caracterização do Estado federativo consiste na sua organização específica, em que os poderes Executivo e Legislativo estão divididos em um órgão central, com competência em todo o território nacional, cuja atividade legislativa participam representantes dos Estados-membros, e em vários órgãos locais, com competência restrita a seus respectivos territórios (KELSEN, 2013, p. 07/08), o que permite classificar as normas em nacionais, federais, estaduais, municipais ou distritais.

A transposição, repetição ou remissão de normas entre
ordens jurídicas distintas é fenômeno frequente no fe-
deralismo brasileiro, diante da primazia da Constituição
Federal sobre as demais ordens jurídicas e o mimetismo
normativo decorrente da fragilidade dos entes subnacio-
nais, sendo frequente que as leis fundamentais das ordens
estaduais, distritais e municipais reproduzam literalmente
enunciados normativos presentes na Constituição Federal
ou incorporem, por remissão, conteúdos constantes de
enunciados constitucionais nacionais. Essa transposição
normativa pode ser implícita ou expressa e, neste último
caso, obrigatória ou voluntária. (MODESTO, 2014, p. 202).

As normas que a Constituição Federal determina, explícita ou 
implicitamente, que sejam observadas pelo Estado, devem ser transplantadas para as Constituições Estaduais (normas de reprodução), ainda que não sejam transcritas em seu texto, vez que são partes integrantes dessas por determinação de um comando maior.

As normas de reprodução obrigatória revelam um comando limitador do poder constituinte decorrente, responsável pela elaboração das Constituições Estaduais, na medida em que vedam que sejam estabelecidas normas constitucionais estaduais contrárias ou diferentes do paradigma estabelecido na Constituição Federal. Tais normas decorrem da imposição do princípio da simetria, ou do conteúdo nítido de norma com caráter nacional obrigatório.

As normas de reprodução obrigatória, quando expressas, garantem maior estabilidade e segurança às limitações impostas ao poder constituinte decorrente, por serem mais facilmente aferidas. Por exemplo, os artigos $27 \S 1^{\circ}, 125 \S 2^{\circ}$ e 75 da Constituição Federal.

Há, também, normas implícitas, a exemplo das regras de repartição de competências previstas na Constituição Federal. É que, a competência, sob o aspecto positivo, consiste numa autorização ou legitimação para a prática de atos jurídicos e, sob o prisma negativo, numa limitação, na medida em que os atos praticados fora do âmbito de competência são inválidos, irregulares ou ineficazes, por excesso ou desvio de poder (MIRANDA, 2007, p. 166). Assim sendo, ao prever que determinadas matérias sejam de competência da União ou dos Municípios, o constituinte promove a exclusão dessas do âmbito de competência dos Estados-membros.

É possível dividir as normas de reprodução obrigatórias quanto à função que desempenham, podendo elas ser normas de vedação ou normas de comando. As primeiras proíbem o Estado de adotar determinados atos ou procedimentos. Já as segundas determinam, diretamente, que a Constituição Estadual adote certos princípios em seu texto (SILVA, 1997).

Quanto às demais normas da Constituição Federal, as mesmas 
poderão ou não ser copiadas pelos Estados em suas Constituições. As normas de imitação expressam a parcela da autonomia normativa dos Estados-membros, junto com as normas inovadoras, de livre criação do poder constituinte decorrente, é dizer, que não estão previstas na Constituição Federal e não estão vedadas por ela. No caso das normas de imitação, o constituinte decorrente demonstra claramente sua vontade de reproduzir e transpor para a Constituição Estadual enunciados da Constituição Federal, incorporando-os ao texto constitucional local. Por isso, são normas que podem ser revogadas, modificadas ou substituídas sem infração à ordem constitucional nacional (MODESTO, 2014, p. 203).

Para o presente estudo, interessam as normas de reprodução obrigatória que, quanto ao conteúdo, podem veicular princípios constitucionais sensíveis, princípios constitucionais estabelecidos e princípios constitucionais extensíveis (BULOS, 2010, p. 416).

\subsection{Princípios constitucionais sensíveis}

Os princípios constitucionais sensíveis, ou princípios constitucionais enumerados, ou princípios constitucionais de intervenção, estão enumerados no art. 34, VII da Constituição Federal de 19886 , e a inclusão de normas na Constituição Estadual que sejam contrárias a esses princípios poderá dar ensejo a Ação Direta de Inconstitucionalidade interventiva, proposta pelo Procurador-Geral da República ao Supremo Tribunal Federal, de acordo com o art. 36, III da Constituição Federal. Aliás, as causas de intervenção federal podem servir de auxílio na identificação das normas de reprodução obrigatória pelas Constituições Estaduais, sem, contudo, entendê-las como determinantes para a aferição dessas normas. Deve-se buscar no texto

6 Os princípios tidos por sensíveis, segundo o preceito normativo do art. 34, VII, CF/1988, são: a) forma republicana, sistema representativo e regime democrático; b) direitos da pessoa humana; c) autonomia municipal; d) prestação de contas da administração pública, direta e indireta; e) aplicação do mínimo exigido da receita resultante de impostos estaduais, compreendida a proveniente de transferências, na manutenção e desenvolvimento do ensino e nas ações e serviços públicos de saúde. 
constitucional quais dessas normas podem, efetivamente, limitar o constituinte na elaboração da Constituição do Estado-membro. Mas não são apenas os princípios elencados no art. 34 da Constituição Federal de 1988 que constituem os chamados princípios sensíveis. Outros princípios quando violados também podem ensejar a intervenção na ordem Estadual, por meio da Ação Direta de Inconstitucionalidade ou outros instrumentos do controle abstrato de normas.

\subsection{Princípios constitucionais extensíveis}

Os princípios constitucionais extensíveis são normas implícitas que, a princípio, dizem respeito à organização da União, mas cuja aplicação se estende aos Estados, como se verifica nos artigos 28, 75 e 93, V da CF/1988. Araújo (2008, p. 168) explica que os princípios constitucionais são normas extraídas do próprio ordenamento jurídico, cuja consolidação, como norma, muito se deve à sua constitucionalização, e que a identificação de tais normas demanda um esforço interpretativo do Supremo Tribunal Federal, atuando, nesse caso, como protagonista do processo de criação da norma.

O Supremo Tribunal tem-se utilizado do princípio da simetria para determinar aos Estados-membros a necessidade ou a possibilidade de reprodução de um modelo federal de organização dos poderes. Nesse sentido, o princípio da simetria se caracteriza como princípio de interpretação da nova hermenêutica constitucional, cuja finalidade é identificar as normas de extensão a serem necessariamente reproduzidas pelas Constituições estaduais, bem como as normas da Constituição Federal de reprodução facultativa, mas que se baseiam num modelo federal válido para os Estados-membros, "funcionando, inclusive, como argumento de exclusão das vedações para reprodução desses mesmos modelos" (ARAUJO, 2008, p. 174).

Essa forma de interpretação revela, grosso modo, uma tendência à centralização, à concentração de poder, tendo em vista a imposição 
aos ordenamentos locais de regras de âmbito federal, pela extensão do texto da Constituição Federal, de matérias antes deixadas, em linha de princípio, à organização autônoma do Estado-membro.

Mas é importante que o intérprete tenha em mente que essa imposição das regras de âmbito federal ao ordenamento local deve ser bem mensurada e evitada, até, a fim de não subverter a ordem trazida pela própria Constituição, na medida em que privilegia as peculiaridades do ente federativo, do interesse local, nas regras de repartição de competência, deixando à União somente a disciplina geral.

Exemplo disso, vê-se em julgado recente (ADI 1077/RS), no qual o Supremo Tribunal Federal, analisando lei do Rio Grande do Sul que dispõe sobre entidades municipais legitimadas a integrar órgão da administração pública estadual ou firmar convênios com o Estado-membro, deu procedência ao pedido, em razão da violação aos princípios da autonomia municipal e da isonomia. Na ocasião, o Ministro Gilmar Mendes explanou que a Corte tem entendido que, consoante o princípio da simetria, cabe ao Governador do Estado a iniciativa de lei que disponha sobre criação, estruturação e atribuições das secretarias e de órgãos da administração pública estadual. Contudo, argumentou que aos municípios é conferida competência constitucional para legislar sobre assuntos de interesse local, e que, naquele caso, houve violação ao princípio constitucional da isonomia, previsto no art. $5^{\circ}$, caput, da Constituição Federal, uma vez que concebe a Federação das Associações de Municípios do Rio Grande do Sul - FAMURS - como única entidade habilitada a integrar órgãos colegiados da administração pública estatal, ou indicar representante para tanto, e exclusivamente legitimada a firmar convênios com o poder público estatal, afastando as demais associações de municípios que àquela Federação não sejam filiados, e inclusive, os municípios individualmente, da possibilidade de representarem seus interesses frente ao poder público estadual, o que evidencia, ademais, afronta ao primado da autonomia municipal. 


\subsection{Princípios constitucionais estabelecidos}

Os princípios constitucionais estabelecidos são regras e normas previamente estabelecidas pela Constituição Federal, que limitarão a atividade do poder constituinte estadual, revelando, antes mesmo da elaboração da Constituição Estadual, o regime normativo que será adotado em algumas matérias nas Cartas Estaduais, como as normas que versam sobre sistema tributário, repartição de competências, organização dos Poderes, direitos políticos, nacionalidade, direitos e garantias individuais, direitos sociais, ordem econômica, educação, família e cultura. Alguns princípios estabelecidos geram limitações expressas, outros, limitações implícitas e, ainda, limitações decorrentes.

Tanto as limitações expressas quanto as limitações implícitas podem ser vedatórias ou mandatórias. As primeiras - limitações expressas vedatórias - dão ensejo a proibições aos Estados-membros, como por exemplo, os artigos 19 e 150 da CF/1988. Já as limitações expressas mandatórias, referem-se a princípios que deverão ser adotados nas Cartas Estaduais, como os princípios que regem a Administração Pública, é dizer, a essência dos artigos 37 e 41 da Constituição Federal.

São exemplos de limitações implícitas vedatórias as regras de repartição de competências, quando a Constituição Federal estabelece as competências privativas da União e dos Municípios, o que exclui, por conseguinte, a atuação dos Estados nessas matérias. A indicação de regras de competência, nesse caso, de forma indireta, envolve a limitação da capacidade organizatória dos Estados. Implica em limitação implícita mandatória, a necessidade de o poder constituinte estadual respeitar o princípio da divisão de poderes, que se acha expressa no art. $2^{\circ}$ da Constituição Federal, bem como nos artigos 27 e 28, que se revelam, também, como normas de preordenação institucional (SILVA, 1997). 
As limitações decorrentes são as extraídas dos princípios do sistema constitucional adotado (ex. Princípio federativo), como a ideia de igualdade dos Estados do ponto de vista da sua organização legal e constitucional, donde nenhum privilégio será concedido apenas a um ou alguns Estados.

\section{ANÁLISE DA JURISPRUDÊNCIA DO SUPREMO TRIBUNAL FEDERAL}

Foi realizado um levantamento das decisões do Supremo Tribunal Federal, com o intuito de conhecer o entendimento da Corte de quais princípios constitucionais evidenciam normas de reprodução obrigatória e se, na aplicação de tais princípios, há uma ponderação desses com o princípio federativo, que demanda a observância da autonomia estadual. Para alcançar esse objetivo, fez-se a busca jurisprudencial no sítio eletrônico do Supremo Tribunal Federal dos termos "princípios sensíveis", "princípios extensíveis", "simetria" e "autonomia estadual", de julgados recentes, no ano de 2015, até 12/12/2015 (data em que a pesquisa foi finalizada), em ações de controle direto de constitucionalidade. A análise restringiu-se a decisões do plenário, por revelarem um entendimento mais consolidado da Corte como um todo. Verificou-se que as decisões apontadas no resultado das buscas não distinguem se a questão diz respeito a aplicação de princípios sensíveis ou extensíveis, tampouco de princípios constitucionais estabelecidos, conforme a classificação doutrinária das normas de repetição obrigatória. Das palavras-chaves utilizadas na pesquisa, verificou-se que "autonomia estadual" foi a que apresentou maior número de resultados ${ }^{7}$.

7 A pesquisa jurisprudencial no site do Supremo Tribunal Federal, julgados no período de 01/01/2015 a 12/12/2015, utilizando por filtros o órgão julgador "plenário" e a palavra-chave "simetria" foram listadas as seguintes ações de controle de constitucionalidade: ADI 1077 / RS; ADI 821 / RS; ADI 2314 / RJ; ADI 253 / MT; ADI 4552 MC / DF; ADI 4284 / RR; ADI 4792 / ES; ADI 4791 / PR. A aposição do termo "autonomia estadual" alcançou 14 resultados, dos quais dizem respeito ao controle de constitucionalidade de norma estadual em face da Constituição Federal: ADI 1077 / RS; ADI 2314 / RJ; ADI 253 / MT; ADI 5081 / DF; ADO 28 / SP; ADI 4552 MC / DF; ADI 3477 / RN; ADI 4060 / SC; ADI 4792 / ES; ADI 4791 / PR; ADI 4900 / DF. Alterando o termo da busca para "princípios extensíveis", nenhum documento foi encontrado. Com o termo "princípios sensíveis" foi localizado tão somente ADI de lei federal. 
Contudo, o fato de esse indexador ser o de maior frequência não necessariamente indica a prevalência da autonomia estadual sobre os demais princípios constitucionais, mas revela que a mesma tem sido objeto de consideração por parte do Supremo Tribunal Federal, na aplicação do princípio da simetria, de forma mais moderada, prestigiando o princípio federativo.

Na ADI 4900, o voto originário do Relator Teori Zavaski teve por sustentáculo o fato de que o conteúdo normativo do art. 37, § 12, da CF não impõe nenhum mandamento a ser seguido pelos Estados e pelo Distrito Federal quanto ao teto remuneratório, apenas facultando-lhes a, por emenda constitucional, adotar o modelo adotado no âmbito federal, de teto único.

Com isso, o teto remuneratório único, não expressaria um comando a ser cumprido, mas mera faculdade a ser exercida de acordo com a autonomia de cada ente. Eventual dessintonia entre eles, se existente, seria de caráter meramente indireto, louvando a autonomia estadual, nesse sentido:

(...) Ao discriminar tetos aprioristicamente diferenciados para União, Estados-membros, Distrito Federal e Municípios - substituindo o referencial único ditado pela EC 19/98 por regras específicas adaptadas a cada nível federativo e a cada instância de poder - a redação dada ao art. 37, XI, pela EC 41/03 parece ter buscado exortar os entes periféricos a proceder de forma particularizada quanto à limitação da remuneração do serviço público, encaminhando-os para soluções compatíveis com as respectivas realidades financeiras. (...) Infere-se, portanto, que a EC 41/03 não enunciou uma restrição explícita à autonomia dos entes federativos para o estabelecimento de tetos remuneratórios inferiores aos previstos de modo geral no texto do art. 37, XI, da CF. Tanto isso é verdade que, com a posterior inclusão do § 12 no art. 37 da CF, o constituinte derivado facultou aos Estados-membros e Distrito Federal a adoção, em seus domínios, de teto único correspondente ao subsídio dos Desembargadores Estaduais.

Ora, se desde a EC 47/05 a própria Constituição permite a adoção, pelos Estados, de um teto mais dilatado do que aquele previsto, em princípio, pelo art. $37, \mathrm{XI}$, da $\mathrm{CF}$, deve ela consentir, com maior razão, com o estabelecimento de tetos estaduais mais compactos do que os previstos 
originalmente no mesmo art. 37, XI, possibilitando, assim, que os entes federados exerçam livremente a autonomia que lhes é garantida pelo pacto federativo (...).

Reconheceu a Corte que a Constituição Federal possui regra especial que detalha a incidência do teto de acordo com as respectivas categorias da estrutura judiciária nacional. Nesse caso, o art. 93, $\mathrm{V}$, espelha uma regra sobre o escalonamento da remuneração na magistratura, impedindo que a diferença de ganhos entre desembargadores e juízes posicionados na última categoria da magistratura estadual seja superior a dez por cento. O voto cita por precedente o julgamento da MC na ADI 2087, na qual o Min. Sepúlveda Pertence fez uma importante advertência a respeito da ascendência do art. 93, V, da CF sobre a autonomia dos Estados e Municípios para definir tetos, ocasião em que o Supremo Tribunal Federal firmou interpretação conforme dos arts. 37, XI, e § 12, da Constituição Federal segundo a qual seria aparentemente inconstitucional distinguir limites diferentes para a magistratura estadual e federal, tendo em vista o caráter nacional do Poder Judiciário.

Na ADI 4791, sobre competência para dispor sobre processo e julgamento de crimes de responsabilidade, reiterou-se a posição do Supremo Tribunal Federal no sentido de considerar legítimas as normas de Constituições Estaduais que subordinam a deflagração formal de um processo acusatório contra o Governador do Paraná a um juízo político da Assembleia Legislativa local. O Min. Celso de Mello, acompanhando o voto do Relator, discorreu que a ideia fundamental que motivou essa orientação jurisprudencial traduz a consagração da autonomia institucional dos Estados-membros, valor constitucional básico que informa e dá consistência à própria teoria da Federação, destacando a importância político-jurídica dessa prerrogativa, que é inderrogável, por se tratar de "valor essencial e conatural à compreensão do sistema federativo" (ADI 4791, Relator(a): Min. TEORI ZAVASCKI, Tribunal Pleno, julgado em 12/02/2015, PROCESSO 
ELETRÔNICO DJe-076 DIVULG 23-04-2015 PUBLIC 24-04-2015).

Também sobre a incompetência dos Estados-membros para legislar sobre processamento e julgamento de crimes de responsabilidade (art. 22, inc. I, da Constituição da República), e a constitucionalidade das normas estaduais que, por simetria, exigem a autorização prévia da Assembleia Legislativa como condição de procedibilidade para instauração de ação contra Governador (art. 51, inc. I, da Constituição da República), a Min. Carmen Lúcia, na ADI 4792/ES (Julgado em 12/02/2015, PROCESSO ELETRÔNICO Dje-076, DIVULG 23-04-2015, PUBLIC 24-04-2015), sustentou que

O modelo de federalismo de equilíbrio adotado no Brasil acolhe o princípio da simetria, segundo o qual a principiologia harmoniza as estruturas e as regras que formam o sistema nacional e os sistemas estaduais, de modo a não desconstituir os modelos adotados no plano nacional e nos segmentos federados em suas linhas mestras. Nesse quadro, o equilíbrio federativo, vem com a unidade que se realiza na diversidade congregada e harmoniosa.

Reconhecida no julgado a necessidade de observância integral pelos Estados-membros dos princípios republicano e o federativo, os quais concretizam as normas constitucionais que autorizam a elaboração de normas estaduais à luz da autonomia que lhes é assegurada:

(...) o exercício da autonomia legislativa pelo Estado do Espírito Santo, longe de evidenciar as inconstitucionalidades anunciadas, configura uma expressão do federalismo cooperativo, que não desconhece a circunstância segundo a qual "as novas relações de poder amparam-se não só na noção de legalidade, mas cumprem também as expectativas de legitimidade, revelando-se compromissadas com a noção de pluralismo que lhe é ínsita e que têm nas alternâncias do jogo político - base da noção de interdependência - , a possibilidade de serem sempre construídas e desconstruídas (Bernardes, Wilba Lúcia Maia. Os desdobramentos do federalismo cooperativo alemão: uma rica experiência de releituras. Em: Estudos de direito constitucional: homenagem ao professor Ricardo Arnaldo Malheiros Fiuza. Belo Horizonte: Del Rey, 2009. p. 216). 
Vê-se, assim, alguns exemplos de como o Supremo Tribunal Federal tem entendido a questão das normas de repetição obrigatória como limitadoras da autonomia estadual, de como os artigos 25 da Constituição Federal e 11, do ADCT, determinam a observância, pelos estados, dos princípios constitucionais, sem, contudo, atuar como amarra absoluta às Constituições Estaduais. O Estado Democrático brasileiro tem como cláusula pétrea constitucional a separação, e a harmonia entre os poderes, consubstanciada em princípio explícito e instrumentalizada em regras constitucionais de competência. A Constituição, ao conferir aos Estados-membros a capacidade de auto-organização e de autogoverno, impõe a observância obrigatória de vários princípios, contudo, a determinação de observância dos princípios constitucionais não significa que cabe ao constituinte estadual apenas copiar as normas federais, pois se, por um lado, o federalismo estabelece a perda da soberania no momento do ingresso do Estado como ente federativo, por outro, preserva a autonomia política limitada deste.

\section{CONCLUSÃO}

As normas de repetição obrigatória têm um papel limitador da autonomia estadual, reflexo que é da própria organização federativa do Estado, donde o novo Estado formado deve obrigatoriamente, para ser considerado Estado federado, ter assegurada sua autonomia, de acordo com os parâmetros encerrados pela Constituição Federal, que lhe autoriza e concede poder para autogerir e determinar-se, de acordo com seus próprios interesses, mas sem se afastar do modelo essencial traçado originariamente.

O princípio federativo impõe que os Estados guardem observância aos princípios constitucionais da República Federativa do Brasil, porém esse mesmo princípio veda o engessamento do pensamento jurídico. Não existe um rol taxativo de quais normas estabelecidas 
na Constituição Federal os Estados-membros devem reproduzir compulsoriamente em seus textos constitucionais. O Supremo Tribunal Federal, nos julgados mais recentes, tem-se mostrado sensível à necessidade de se preservar a autonomia estadual e local, prestigiando as iniciativas normativas regionais, a menos que ofendam norma expressa e inequívoca da Constituição de 1988.

Em linhas gerais, o federalismo envolve a partilha vertical do poder entre diversas entidades políticas autônomas, que coexistem no interior de um único Estado soberano. Na tentativa de conciliar a unidade com a diversidade, se destaca a necessidade de promover a efetiva autonomia política dos entes federativos, que se traduz nas prerrogativas de autogoverno, de auto-organização e de autoadministração. Embora a federação brasileira ainda se revele altamente centralizada, considerando que a partilha de competências entre os entes da federação (CRFB, arts. 21 a 24) concentra grande quantidade de matérias sob a autoridade privativa da União, o Supremo Tribunal Federal ao exercer o controle de constitucionalidade de lei ou ato federal e estadual, tem aplicado o princípio da simetria de forma moderada.

Se, a princípio, a tensão federativa mostra-se mais tendenciosa à centralização da autoridade política e administrativa na União, a Corte Constitucional tem prestigiado as iniciativas regionais e locais na maior medida possível, salvaguardando apenas as situações de ofensa a norma expressa e inequívoca da Constituição.

Considerando que as normas de repetição obrigatória tem papel limitador da autonomia estadual, sua aplicação deve ter por norte o respeito à forma de organização do Estado, ou seja, o pacto federativo. Desta forma, a Constituição Federal confere criatividade ao constituinte estadual para gerir seus próprios interesses, observando, contudo, os ditames da Constituição Federal. A reprodução pelos Estados do conteúdo de certas normas voltadas para a União, com base no princípio da simetria, demanda parcimônia de modo a preservar a concepção de autonomia Estadual.

Equilibrar essas características (criação/repetição obrigatória) é 
medida que se impõe como fundamental para efetivar a harmonia entre os entes federativos. Essa orientação se amolda à noção de federalismo, como sistema que visa a promover a unidade coordenada dos estados, mas, também, o pluralismo nas formas de organização política, sendo esse (o pluralismo político) um dos fundamentos da República Federativa do Brasil.

\section{THE ROLE OF LEGAL PROVISIONS OF MANDATORY REPLICATION IN MEMBER-STATES' AUTONOMY}

\section{ABSTRACT}

The legal provisions of mandatory replication are those of compulsory observance in member States' constitutional texts and are derived from the subordination to the basic principles of the Constitution of the Republic, in accordance to the legal provision inserted in the Article 25, caput, of Federal Constitution of 1988. Concerning such norms the constituent is required to insert them into the Constitution of the State in a transplantation process. The norms of mandatory replication are spread throughout the whole constitutional text and, quite often, are implicit, what makes it difficult for interpreters to determine whether they must be applied or not. Then, it is necessary to answer the following questions: which role is played by provisions of mandatory replication? How they can be identified? What are the constitutional parameters that must be observed in order to avoid infringement of member States' autonomy? The application of those principles bears a limitation onto States' autonomy and therefore, must comply with the federative principle, in order not to annihilate the Member-States' autonomy, being such - the autonomy of federative entities - the intrinsic characteristic of this form of State. The research was documentary and bibliographic, based upon books, journals articles, statutes and regulations, aiming at enhancing understanding of the subject, in a exploratory, descriptive, qualitative and explanatory approach. After an introduction, the text examines different conceptions of States' autonomy and of provisions 
of mandatory replication. Then, it presents the results of an analysis of recent rulings by Brazil's Supreme Court. It comes to the conclusion that provisions of mandatory replication derive from the need to harmonize the Federation and impose a limitation of powers to Member-States and, therefore, must be used with moderation, once their enforcement cannot derogate States' autonomy, specially employing balancing of the principles of autonomy and of simetry.

Keywords: federalism; norms of mandatory replication; Member-States' autonomy in Federal States.

\section{REFERÊNCIAS}

BULOS, Uadi Lammego. Curso de direito constitucional. $5^{\text {a }}$ ed. São Paulo: Saraiva, 2010.

COELHO, Inocêncio Mártires. Elementos de teoria da Constituição e de interpretação constitucional. In: MENDES, Gilmar Ferreira; COELHO, Inocêncio Mártires; e BRANCO, Paulo Gustavo Gonet. Hermenêutica constitucional e direitos fundamentais. p. 15-28. Brasília: Brasília Jurídica, 2000.

ISMAEL, Ricardo. Hamilton, Madison e Jay: os pressupostos teóricos do federalismo moderno. In: FERREIRA, Lier Pires; GUANABARA, Ricardo; e JORGE, Vladymir Lombardo (Org.). Curso de ciência política: grandes autores do pensamento político moderno e contemporâneo. Cap. 9. p. 227/249. Rio de Janeiro: Campus, 2009.

KELSEN, Hans. Jurisdição constitucional. São Paulo: Martins Fontes, 2013. p. 319.

MIRANDA, Jorge. Teoria do estado e da constituição. Rio de Janeiro: Forense, 2007.

MORAES FILHO, José Filomeno de. Congresso constituinte, constituição dirigente e estado de bem-estar. Tese (Doutorado) - Curso de Direito Econômico e Financeiro, Faculdade de Direito, Universidade de São Paulo, São Paulo, 2009.

SILVA, José Afonso. Curso de direito constitucional positivo. $14^{\mathrm{a}}$ ed. São Paulo: Malheiros, 1997. 


\section{SÍTIOS ELETRÔNICOS}

ARAUJO, Marcelo Labanca Correia de. A construção da federação brasileira pela jurisdição constitucional: um estudo sobre a utilização do princípio da simetria na jurisprudência do Supremo Tribunal Federal. Tese (Doutorado) - Programa de Pós-Graduação em Direito, Faculdade de Direito do Recife, Universidade Federal de Pernambuco, Recife, 2008. Disponível em: <http://repositorio.ufpe.br/bitstream/handle/123456789/4141/arquivo6240_1.pdf?sequence=1\&isAllowed=y>. Acesso em: 10 dez. 2015.

CLARK, R. Bradford. The supremacy clause as a constraint on federal power. George Washington University Law Review, Vol. 71. 2003. P. 1 - 43. Disponível em: http://scholarship.law.gwu.edu/cgi/viewcontent.cgi?article =1474\&context=faculty_publications. Acesso em: 12 abr. 2016.

HORTA, Raul Machado. Repartição de competências na Constituição Federal de 1988. Revista da Faculdade de Direito da Universidade Federal de Minas Gerais. Belo Horizonte, v. 33, n. 33, p. 249-274, out. 1991. Semestral. Disponível em: <http://www.direito.ufmg.br/revista/index.php/revista/ article/viewFile/1431/1360>. Acesso em: 24 nov. 2015.

MODESTO, Paulo. As normas de reprodução, imitação e remissão como parâmetro de controle de constitucionalidade nos Estados-membros da Federação e o papel das leis orgânicas municipais. Revista brasileira de direito público - RBDP. Belo Horizonte, ano 12, n. 46, p. 201-213, jul./set. 2014. Disponível em: <http://pt.scribd.com/doc/280974430/AS-NORMAS-DE-REPRODUCAO-IMITACAO-E-REMISSAO-COMO-PARAMETRO-DE-CONTROLE-DE-CONSTITUCIONALIDADE-NOS-Estados-membroS-DA-FEDERACAO-E-O-PAPEL-DAS-LEIS-ORG\#Scribd>. Acesso em: 07 dez. 2015.

MONTESQUIEU. O espírito das leis. Segunda Parte, Livro Nono, capítulo I. Disponível em: <http://www.dhnet.org.br/direitos/anthist/marcos/ hdh_montesquieu_o_espirito_das_leis.pdf>. Acesso em: 19 nov. 2015. 